\title{
Effect of adiposity, season, diet and calcium or vitamin $D$ supplementation on the vitamin D status of healthy urban African and Asian-Indian adults
}

\author{
Jaya A. George ${ }^{1 *}$, Shane A. Norris ${ }^{2}$, Hendrick E. van Deventer ${ }^{3}$, John M. Pettifor ${ }^{2}$ and Nigel J. Crowther ${ }^{1}$ \\ ${ }^{1}$ National Health Laboratory Service, Department of Chemical Pathology, Faculty of Health Sciences, University of the \\ Witwatersrand, 7 York Road, Parktown, Johannesburg 2193, South Africa \\ ${ }^{2}$ MRC/Wits Developmental Pathways for Health Research Unit, University of the Witwatersrand, Johannesburg, South Africa \\ ${ }^{3}$ Lancet Laboratories, Auckland Park, Johannesburg, South Africa
}

(Submitted 13 June 2013 - Final revision received 25 March 2014 - Accepted 2 May 2014 - First published online 30 May 2014)

\begin{abstract}
Vitamin D deficiency has been implicated in the aetiology of infectious diseases and metabolic syndrome. These diseases are prevalent in the African and Asian-Indian populations of South Africa; however, there is limited data on 25-hydroxyvitamin D (25(OH)D) concentrations in these populations. The aim of the present study was to assess the vitamin D status and its predictors in healthy adults in Johannesburg. We assessed the vitamin D status of 730 adult African and Asian-Indian subjects residing in Johannesburg. The contributions of sun exposure, season, dietary intake of $\mathrm{Ca}$ and vitamin $\mathrm{D}$, total body fat and body fat distribution to $25(\mathrm{OH}) \mathrm{D}$ concentrations were assessed. The concentrations of $25(\mathrm{OH}) \mathrm{D}$ were measured by HPLC. The contribution of $25(\mathrm{OH}) \mathrm{D}_{3}$ to total $25(\mathrm{OH}) \mathrm{D}$ concentrations was assessed. The mean age of the subjects was 42.6 (SD 13.1) years (range: $18-65$ ). Concentrations of $25(\mathrm{OH}) \mathrm{D}<30 \mathrm{nmol} / 1$ were found in $28.6 \%$ of the Asian-Indian subjects in comparison with $5.1 \%$ of the African subjects $(P<0.0001)$. Parathyroid hormone (PTH) concentrations were negatively associated with $25(\mathrm{OH}) \mathrm{D}$ concentrations, while season and sun exposure were positive predictors explaining $16 \%$ of the variance in $25(\mathrm{OH}) \mathrm{D}$ concentrations $(P<0.0001)$ in the African subjects. In the Asian-Indian subjects, PTH concentrations were negatively associated with 25(OH)D concentrations, while male sex, season and Ca supplementation were positive predictors and explained $17 \%$ of the variance in $25(\mathrm{OH}) \mathrm{D}$ concentrations $(P<0 \cdot 0001)$. In the multivariate regression analysis, neither total body fat nor body fat distribution was predictive of $25(\mathrm{OH}) \mathrm{D}$ concentrations in either group. In conclusion, factors such as sun exposure, dietary supplement use and ethnicity are important determinants of plasma 25(OH)D concentrations.
\end{abstract}

Key words: 25-Hydroxyvitamin D: Visceral adiposity: Subcutaneous adiposity: Vitamin D supplementation: Calcium supplementation: Vitamin D deficiency: Total body fat

Similar to the rest of sub-Saharan Africa, South Africa is plagued by the burden of chronic infectious diseases including tuberculosis and $\mathrm{HIV}^{(1)}$ as well as a rising burden of non-communicable diseases $^{(2)}$. Recently, studies have shown that vitamin D deficiency or insufficiency is associated with an increased risk of $\mathrm{CVD}^{(3)}$, diabetes ${ }^{(4)}$, cancers $^{(5,6)}$, infections ${ }^{(7)}$ and autoimmune conditions $^{(8)}$ in addition to its classical effects on bone.

Although its definition remains a concern, several studies on vitamin D deficiency across the world suggest that it is a global health problem ${ }^{(9,10)}$. South African studies have been limited to only children ${ }^{(11)}$ or women ${ }^{(12)}$ or hospitalised or ill individuals ${ }^{(7)}$, and the reported prevalence of vitamin D deficiency ranges from $8.0 \%$ in African children to $62.7 \%$ in adults with tuberculosis and/or HIV when using a cut-off value $<50 \mathrm{nmol} / 1$ to define deficiency.
To understand the health risks associated with vitamin D deficiency, it is important have knowledge of the determinants of 25-hydroxyvitamin D $(25(\mathrm{OH}) \mathrm{D})$ concentrations. The objective of the present study was to determine the vitamin D status of two ethnic groups in Johannesburg and to identify the main determinants of $25(\mathrm{OH}) \mathrm{D}$ concentrations in each ethnic group, including body fat mass and body fat distribution. Factors such as sun exposure, age, fat mass, sex, ethnicity and lifestyle may influence the serum concentrations of this vitamin ${ }^{(10,13-15)}$ and may be important contributors to vitamin D status. The serum concentration of $25(\mathrm{OH}) \mathrm{D}$ has been reported to be inversely associated with BMI and with subcutaneous adiposity (SCAT) as well as visceral adiposity $(\mathrm{VAT})^{(16,17)}$. We determined the contributions of $25(\mathrm{OH}) \mathrm{D}_{3}$ and $25(\mathrm{OH}) \mathrm{D}_{2}$ to total $25(\mathrm{OH}) \mathrm{D}$

Abbreviations: 25(OH)D, 25-hydroxyvitamin D; DEQAS, Vitamin D External Quality Assessment Scheme; IQR, interquartile range; PTH, parathyroid hormone; SCAT, subcutaneous adiposity; VAT, visceral adiposity.

* Corresponding author: J. A. George, fax +27 11 4898451, email jaya.george@wits.ac.za 
concentrations using HPLC as several commonly used immunoassays preferentially detect $25(\mathrm{OH}) \mathrm{D}_{3}{ }^{(18)}$.

\section{Methods}

\section{Subjects}

This was a cross-sectional study of ambulatory African and Asian-Indian adults living in the Greater Johannesburg Metropolitan area. Subjects were recruited via carers of the Birth to Twenty cohort ${ }^{(19)}$. Carers were randomly selected from this study cohort and then asked whether they had family members interested in participating in the study. Exclusion criteria were pregnancy, breast-feeding and age below 18 years or above 65 years, impaired renal function as determined by self-reports, and mixed ancestry or Caucasian race. A total of 730 participants were recruited, and prevalence results are reported for 714 subjects (sixteen subjects were excluded either because they did not meet the inclusion criteria or because they had incomplete data). The sample size was calculated to ensure a statistical power of $90 \%$ and a probability of less than 0.05 for detecting a $15 \%$ inter-group difference in $25(\mathrm{OH}) \mathrm{D}$ concentrations. The present study was conducted according to the guidelines laid down in the Declaration of Helsinki. The Human Ethics Committee of the University of the Witwatersrand approved all the procedures involving the subjects. Written informed consent was obtained from each subject. The study was conducted from July 2011 to April 2012.

\section{Biochemical analysis}

Venous blood samples were collected in EDTA tubes for the measurement of $25(\mathrm{OH}) \mathrm{D}$ concentrations after an overnight fast. Plasma 25(OH)D was run on a HPLC system (HPLC Shimadzu LC-10 ADVP; Shimadzu Corporation) with a photodiode array detector using the ClinRep ${ }^{\circledR}$ HPLC Complete Kit for $25(\mathrm{OH}) \mathrm{D}_{2} / \mathrm{D}_{3}$ in plasma and serum (Recipe) ${ }^{(20)}$. The separated $25(\mathrm{OH}) \mathrm{D}_{2}$ and $25(\mathrm{OH}) \mathrm{D}_{3}$ were detected at a wavelength of $264 \mathrm{~nm}$ and chromatograms integrated using peak height. The sum of $25(\mathrm{OH}) \mathrm{D}_{2}$ and $25(\mathrm{OH}) \mathrm{D}_{3}$ was taken as total $25(\mathrm{OH}) \mathrm{D}$. This analysis was carried out in a laboratory that participates in the Vitamin D External Quality Assessment Scheme (DEQAS) and achieved the performance targets set by the DEQAS. The intra-assay and inter-assay $\mathrm{CV}$ for $25(\mathrm{OH}) \mathrm{D}_{3}$ for controls at a mean of $61.7 \mathrm{nmol} / 1$ ranged from 0.36 to $9 \cdot 4 \%$ and those for controls at a mean of $222 \mathrm{nmol} / 1$ ranged from $2 \cdot 1$ to $5 \cdot 5 \%$. For $25(\mathrm{OH}) \mathrm{D}_{2}$, the $\mathrm{CV}$ for the low control (mean $49.2 \mathrm{nmol} / \mathrm{l}$ ) ranged from 6.8 to $9.7 \%$ and that for the high control (mean $199 \mathrm{nmol} / \mathrm{l}$ ) ranged from $1 \cdot 1$ to $5.7 \%$. The limit of quantification was $6.5 \mathrm{nmol} / 1$ for $25(\mathrm{OH}) \mathrm{D}_{3}$ and $11.0 \mathrm{nmol} / \mathrm{l}$ for $25(\mathrm{OH}) \mathrm{D}_{2}$. The level of $25(\mathrm{OH}) \mathrm{D}_{2}$ was below the limit of quantification in $9 \cdot 2 \%$ of the subjects and these cases were assigned a nominal value of 0 . The following values were used to define vitamin $D$ status: $25(\mathrm{OH}) \mathrm{D}$ concentrations $<30 \mathrm{nmol} / \mathrm{l}$, vitamin D deficiency; $25(\mathrm{OH}) \mathrm{D}$ concentrations $=30-49.9 \mathrm{nmol} / \mathrm{l}$, vitamin D insufficiency; 25(OH)D concentrations $>50 \mathrm{nmol} / \mathrm{l}$, vitamin $\mathrm{D}$ sufficiency $^{(17)}$.
Serum creatinine, serum $\mathrm{Ca}$, serum phosphate and alkaline phosphatase concentrations were measured on the ADVIA 1800 (Siemens). The concentrations of parathyroid hormone (PTH) were measured using a chemiluminescent assay on a Centaur autoanalyser (Siemens). The intra-assay CV for PTH was $5.2 \%$ at $4.3 \mathrm{pmol} / 1$ and $3.4 \%$ at $23.7 \mathrm{pmol} / 1$. The reference range in the study laboratory is $1.20-8.85 \mathrm{pmol} / 1$.

\section{Anthropometric measurements}

Height (in $\mathrm{cm}$ ) was measured using a wall-mounted stadiometer (Holtain Limited) and weight (in kg) was measured using a digital scale (Dismed, Inc.). Both instruments were calibrated weekly. The participants wore minimal clothing when being weighed. BMI was calculated as the participant's weight $(\mathrm{kg})$ divided by his or her height squared $\left(\mathrm{m}^{2}\right)$.

Abdominal VAT and SCAT were determined by ultrasound using a LOGIC ultrasound system (GE Healthcare) with a $2-5 \mathrm{MHz}$ 3C-RS curved array transducer ${ }^{(21)}$. Ultrasound visceral adipose tissue thickness was defined as the distance (cm) from the peritoneum to the vertebral bodies, and ultrasound subcutaneous adipose tissue thickness was defined as the depth $(\mathrm{cm})$ from the skin to the linea alba. The scan depth was set at $15 \mathrm{~cm}$ for the visceral fat measurement and at $9 \mathrm{~cm}$ for the subcutaneous fat measurement to visualise the relevant anatomical structures. Both measurements were obtained at the site where the xiphoid line and waist circumference met. A single trained operator took all the measurements.

Total body adipose tissue was quantified by dual-energy X-ray absorptiometry (Hologic, software version 12.5:7; scan region $195 \times 65 \mathrm{~cm}^{2}$ and weight limit $120 \mathrm{~kg}$ ) according to standard procedures, with a $\mathrm{CV}$ of $0.7 \%$ for fat-free tissue mass and that of $1.67 \%$ for fat mass.

\section{Sun exposure}

Sun exposure was determined using a questionnaire, which assessed the participants' recollection of daily sun exposure over the previous week ${ }^{(22,23)}$. There were three options for time spent outdoors every day $(0=\leq 5 \mathrm{~min}, 1=5-30 \mathrm{~min}$ and $2=>30 \mathrm{~min}$ ). There were four options for skin exposure while outdoors ( $1=$ face and hands only; 2 = face, hands, and arms; 3 = face, hands, and legs; and $4=$ bathing suit) A daily sun exposure score $(\min =0 ; \max =8)$ was calculated using the product of the amount of time spent outdoors and the amount of skin exposed. Sun exposure scores obtained for the $7 \mathrm{~d}$ were then summed to obtain the weekly sun exposure score $(\min =0 ; \max =56)$. Seasons of the year, for the statistical analysis, were categorised as winter (June to August), spring (September to November), summer (December to February) and autumn (March to May). This depended on when the study participants were assessed. The average daily sunshine hours for the study period were as follows: $9.4 \mathrm{~h}$, winter; $9.8 \mathrm{~h}$, spring; $7.8 \mathrm{~h}$, summer; $8.4 \mathrm{~h}$, autumn (Communication from the South African Weather Service 26th February 2013). 


\section{Dietary calcium and vitamin D intake}

A trained worker administered a $7 \mathrm{~d}$ FFQ to each participant. Portion sizes were reported in household measures and then converted to weights using standard tables ${ }^{(24)}$. Food intake $(\mathrm{g})$ was calculated for $7 \mathrm{~d}$ to be able to include quantities of less than $1 \mathrm{~g} / \mathrm{d}$ in the analysis. Thereafter, the nutrient content was calculated and expressed as the average amount of nutrients consumed per $\mathrm{d}$ for each participant. For the purpose of the present study, Ca intake was assessed from the intake of dairy products, while vitamin D intake was determined from the intake of only eggs, margarine, butter and fish. In South Africa, there is no mandatory fortification of foods with vitamin D; however, most margarines are vitamin D fortified ${ }^{(11)}$. Vitamin D and Ca supplement use was assessed and recorded as 'yes' or 'no'.

\section{Smoking status, level of education and HIV status}

Current smoking status (yes/no) was assessed during the interview. The level of education attained by the participants was categorised as follows: 0 - did not complete high school and 1 - completed high school and/or attained a post-high school qualification. The prevalence of HIV was quantified by the self-reporting of HIV status by each participant.

\section{Statistical analysis}

Statistical analysis was conducted using the Stata software package version 12 (StataCorp). The Shapiro-Wilk test was used to test for normality. Non-normally distributed data are reported as medians and interquartile ranges (IQR) and normally distributed data as means and standard deviations. Non-normally distributed data were transformed to achieve normality (log transformed or square root) before regression analysis. The Mann-Whitney $U$ test was used to compare differences between the two ethnic groups for non-normally distributed data, the Student $t$ test for normally distributed data and the $\chi^{2}$ test for categorical data. A $P$ value $<0.05$ was considered statistically significant. We compared differences in $25(\mathrm{OH}) \mathrm{D}$ concentrations between the two ethnic groups using ANOVA. Pairwise comparisons were used only if the overall ANOVA results were statistically significant. Bonferroni corrections were used for multiple comparisons.

The main aim of the present study was to identify the principal determinants of $25(\mathrm{OH}) \mathrm{D}$ concentrations in each ethnic group and therefore the data of the African and AsianIndian subjects were analysed separately. Regression analysis was restricted to total $25(\mathrm{OH}) \mathrm{D}$ rather than to $25(\mathrm{OH}) \mathrm{D}_{2}$ and $25(\mathrm{OH}) \mathrm{D}_{3}$ individually. We carried out univariate Spearman's analysis to assess the strength of the relationship of $25(\mathrm{OH}) \mathrm{D}$ concentrations with parameters that are thought to influence $25(\mathrm{OH}) \mathrm{D}$ status. The following were considered as potential predictors based on previous evidence: age ${ }^{(25)}$; season ${ }^{(26)}$; body $\mathrm{fat}^{(27)}$; sun exposure ${ }^{(24)}$; vitamin D or Ca supplementation $^{(28)}$; renal function; smoking status ${ }^{(29)}$; dietary intake of $\mathrm{Ca}$ and vitamin $\mathrm{D}^{(30)}$; PTH concentrations. These as well as anthropometric measures of subcutaneous, visceral and whole-body fat were used as independent variables in separate multivariate models for the African and AsianIndian subjects in which $25(\mathrm{OH}) \mathrm{D}$ was the dependent variable. For each ethnic group, the season during which the lowest $25(\mathrm{OH}) \mathrm{D}$ concentrations were recorded was coded as 1 and the remaining seasons were grouped together and coded as 2. Winter was coded as 1 for the African subjects and spring for the Asian-Indian subjects. A backward stepwise multiple regression analysis was carried out until only variables with a $P$ value $<0.05$ remained. We adjusted all the models for sex and height. Due to collinearity, BMI and total body fat were not included in the same model. We tested for the collinearity of models that included VAT, SCAT and total body fat and found no collinearity as evidenced by a variance inflation factor $<10 \cdot 0$. We also tested for an interaction between ethnicity and body composition variables and found no significant interaction. To facilitate direct comparisons of the strengths of the associations, the results of the regression models are reported as standardised $\beta$-values.

\section{Results}

\section{Demographic variables}

Complete data were available for 714 subjects (371 Africans and 343 Asian-Indians). The demographic and biochemical characteristics of the participants are given in Table 1.

The mean ages of the African and Asian-Indian subjects were similar (41.6 (SD 13.1) years (range 19-65) and 43.5 (SD 13.0) years (range 18-65; $P=0.06$ ), respectively). More Asian-Indian subjects than African subjects had completed high school $(P<0.0001)$, and there were more smokers in the African group than in the Asian-Indian group (34v.17\%, $P<0 \cdot 0001)$. None of the participants was using anti-epileptic medication, but $12.9 \%$ of the Asian-Indian subjects and $1.4 \%$ of the African subjects were on statin therapy. HIV status was determined by self-report: $87 \cdot 7 \%$ of the Black Africans reported their status as negative, $8.5 \%$ reported being HIV positive and $3.7 \%$ reported to have had never been tested; $94.5 \%$ of the Asian-Indians reported their status as negative and $5.5 \%$ reported to have had never been tested. To our knowledge, none of the participants suffered from metabolic conditions likely to affect vitamin D metabolism.

\section{Anthropometry}

Median BMI was in the overweight range for both groups. The Asian-Indian subjects had greater waist circumference, greater total body fat and greater body fat percentage than the African subjects ( $P<0 \cdot 0001$ for all variables). VAT was similar between the two ethnic groups, but the Asian-Indian subjects had greater SCAT than the African subjects (Table 1).

\section{Vitamin D status}

Using the Shapiro-Wilk test, 25(OH)D was found to not be normally distributed. The African subjects had significantly higher $25(\mathrm{OH}) \mathrm{D}$ and $25(\mathrm{OH}) \mathrm{D}_{3}$ concentrations than the Asian-Indian subjects (see Table 1). Sex differences were 
Table 1. Descriptive characteristics of the study participants $\dagger$

(Mean values and standard deviations (parametric data); medians and inter-quartile ranges (IQR; non-parametric data) and percentages)

\begin{tabular}{|c|c|c|c|c|c|}
\hline \multirow[b]{2}{*}{ Variables } & \multicolumn{2}{|c|}{ Africans ( $n$ 371) } & \multicolumn{2}{|c|}{ Asian-Indians ( $n$ 343) } & \multirow[b]{2}{*}{$P$} \\
\hline & Median & IQR & Median & IQR & \\
\hline Age (years) & & & \multirow{2}{*}{\multicolumn{2}{|c|}{43.5}} & 0.06 \\
\hline Mean & \multicolumn{2}{|c|}{41.6} & & & \\
\hline SD & \multicolumn{2}{|c|}{$13 \cdot 1$} & \multicolumn{2}{|c|}{$12 \cdot 9$} & \\
\hline Males (\%) & \multicolumn{2}{|c|}{48} & \multicolumn{2}{|c|}{45} & 0.65 \\
\hline Education: did not complete high school (\%) & \multirow{2}{*}{\multicolumn{2}{|c|}{$\begin{array}{l}57.0 \\
33.8\end{array}$}} & \multicolumn{2}{|c|}{33.0} & $<0.0001$ \\
\hline Smoker (\%) & & & \multicolumn{2}{|c|}{$16 \cdot 6$} & $<0.0001$ \\
\hline BMI $\left(\mathrm{kg} / \mathrm{m}^{2}\right)$ & $26 \cdot 2$ & $21 \cdot 7-31 \cdot 7$ & $26 \cdot 7$ & $23 \cdot 3-31 \cdot 0$ & 0.38 \\
\hline Waist circumference $(\mathrm{cm})$ & 89.0 & $78 \cdot 0-102$ & $95 \cdot 0$ & $85-106$ & $<0.0001$ \\
\hline Visceral adipose tissue thickness $(\mathrm{cm})$ & 4.93 & $3.72-6.34$ & 4.91 & $3.31-6.46$ & 0.48 \\
\hline Subcutaneous adipose tissue thickness $(\mathrm{cm})$ & $2 \cdot 32$ & $1.59-3.44$ & 3.04 & $2.24-3.91$ & $<0.0001$ \\
\hline Total body fat $(\mathrm{kg})$ & 21.5 & $11.9-31.6$ & $24 \cdot 3$ & $18 \cdot 1-32 \cdot 6$ & $<0.0001$ \\
\hline eGFR $\left(\mathrm{ml} / \mathrm{min}\right.$ per $\left.1.73 \mathrm{~m}^{2}\right)$ & & & & & 0.90 \\
\hline Mean & \multicolumn{2}{|c|}{88} & \multicolumn{2}{|c|}{88} & \\
\hline SD & \multicolumn{2}{|c|}{22} & \multicolumn{2}{|c|}{19} & \\
\hline $25(\mathrm{OH}) \mathrm{D}_{3}$ & $62 \cdot 8$ & $45.5-88.5$ & $36 \cdot 7$ & $33 \cdot 6-62 \cdot 7$ & $<0.0001$ \\
\hline $25(\mathrm{OH}) \mathrm{D}(\mathrm{nmol} / \mathrm{l})$ & 64.9 & $46 \cdot 4-89 \cdot 4$ & $41 \cdot 2$ & $28 \cdot 4-56 \cdot 8$ & $<0.0001$ \\
\hline $25(\mathrm{OH}) \mathrm{D}_{3}$ females $(\mathrm{nmol} / \mathrm{l}) \ddagger$ & $56 \cdot 8^{* * *}$ & $40 \cdot 4-80 \cdot 1$ & $32 \cdot 4^{\star \star *}$ & $19 \cdot 0-48 \cdot 9$ & $<0.0001$ \\
\hline $25(\mathrm{OH}) \mathrm{D}$ females $(\mathrm{nmol} / \mathrm{l})$ & $58 \cdot 3^{\star \star *}$ & $42 \cdot 9-85 \cdot 6$ & $35 \cdot 8^{\star * *}$ & $23.0-54.5$ & $<0.0001$ \\
\hline $25(\mathrm{OH}) \mathrm{D}_{3}$ males $(\mathrm{nmol} / \mathrm{l}) \ddagger$ & $72 \cdot 4$ & $51 \cdot 1-94 \cdot 1$ & $43 \cdot 9$ & $30.6-58.9$ & $<0.0001$ \\
\hline $25(\mathrm{OH}) \mathrm{D}$ males $(\mathrm{nmol} / \mathrm{l})$ & $73 \cdot 2$ & $51 \cdot 2-94 \cdot 1$ & 45.4 & $33 \cdot 6-62 \cdot 7$ & $<0.0001$ \\
\hline $\mathrm{Ca}(\mathrm{mmol} / \mathrm{l})$ & & & & & 0.21 \\
\hline Mean & \multicolumn{2}{|c|}{$2 \cdot 27$} & \multicolumn{2}{|c|}{$2 \cdot 26$} & \\
\hline SD & \multicolumn{2}{|c|}{0.09} & \multicolumn{2}{|c|}{$0 \cdot 11$} & \\
\hline $\mathrm{Pi}(\mathrm{mmol} / \mathrm{l})$ & \multirow{2}{*}{\multicolumn{2}{|c|}{$1 \cdot 10$}} & & & 0.30 \\
\hline Mean & & & \multicolumn{2}{|c|}{$1 \cdot 10$} & \\
\hline SD & \multicolumn{2}{|c|}{0.17} & \multicolumn{2}{|c|}{0.15} & \\
\hline PTH (pmol/l) & 4.70 & $3 \cdot 30-6 \cdot 50$ & 4.85 & $3.61-6.92$ & 0.09 \\
\hline Dietary Ca intake $(\mathrm{mg} / \mathrm{d})$ & 223 & $98 \cdot 6-427$ & 336 & $204-487$ & $<0.0001$ \\
\hline Dietary vitamin $D$ intake $(\mu \mathrm{g} / \mathrm{d})$ & 2.96 & $1.50-5 \cdot 12$ & 1.17 & $0.55-2.11$ & $<0.0001$ \\
\hline Vitamin D deficient $(\%)$ & \multicolumn{2}{|c|}{5.90} & \multicolumn{2}{|c|}{$30 \cdot 3$} & $<0.0001$ \\
\hline Weekly sun exposure score & & & & & 0.23 \\
\hline Mean & & & & & \\
\hline SD & & & & & \\
\hline Ca supplement use (\%) & & & & & $<0.0001$ \\
\hline Vitamin D supplement use (\%) & & & & & $<0.0001$ \\
\hline
\end{tabular}

observed in $25(\mathrm{OH}) \mathrm{D}$ as well as $25(\mathrm{OH}) \mathrm{D}_{3}$ concentrations. The prevalence of vitamin $\mathrm{D}$ deficiency $(25(\mathrm{OH}) \mathrm{D}$ concentrations $<30 \mathrm{nmol} / \mathrm{l}$ ) was $28.6 \%$ in the Asian-Indian subjects compared with just over $5 \%$ in the African subjects (Table 1) and was highest in the Asian-Indian women $(37.9 \%$ in Asian-Indian females and $17.9 \%$ in Asian-Indian males, $P<0.0001 ; 6.7 \%$ in African females and $2.8 \%$ in African males, $P=0.08$ ).

In both ethnic groups, 94.5 (sD 17.9) \% of all the 25(OH)D measured was $25(\mathrm{OH}) \mathrm{D}_{3}$. Mean serum $\mathrm{Ca}$ and phosphate concentrations were normal and similar between the two groups. Plasma PTH concentrations were above the laboratory reference range in $12 \%$ of the African subjects and $14 \%$ of the Asian-Indian subjects.

\section{Seasonal differences}

As expected, seasonal differences were observed in $25(\mathrm{OH}) \mathrm{D}$ concentrations in both groups. Plasma $25(\mathrm{OH}) \mathrm{D}$ concentrations were $40-60 \%$ higher in subjects from whom blood samples were collected in autumn than in those from whom blood samples were collected in winter/spring (Fig. 1). This variation was due to changes in $25(\mathrm{OH}) \mathrm{D}_{3}$ concentrations, with all the participants exhibiting maximal $25(\mathrm{OH}) \mathrm{D}_{3}$ concentrations in autumn. As expected, no significant seasonal difference was observed in $25(\mathrm{OH}) \mathrm{D}_{2}$ concentrations. The prevalence of $25(\mathrm{OH}) \mathrm{D}$ deficiency $(<30 \mathrm{nmol} / \mathrm{l})$ per season was as follows: $8 \%$ in winter; $23 \%$ in spring; $13 \%$ in summer; $<1 \%$ in autumn. The prevalence of $25(\mathrm{OH}) \mathrm{D}$ insufficiency $(<50 \mathrm{nmol} / \mathrm{l})$ per season was as follows: $40 \%$ in winter; $31 \%$ in spring; $30 \%$ in summer; $4 \%$ in autumn.

Sun exposure scores were not significantly different between the ethnic groups but were different by sex: African males - 18.80 (SD 8.49) and African females - 16.73 (SD 11.33) $(P=0.02)$; Asian-Indian males - 18.71 (SD 10.19) and AsianIndian females -14.43 (sD 8.46) $(P=0.0001)$. 


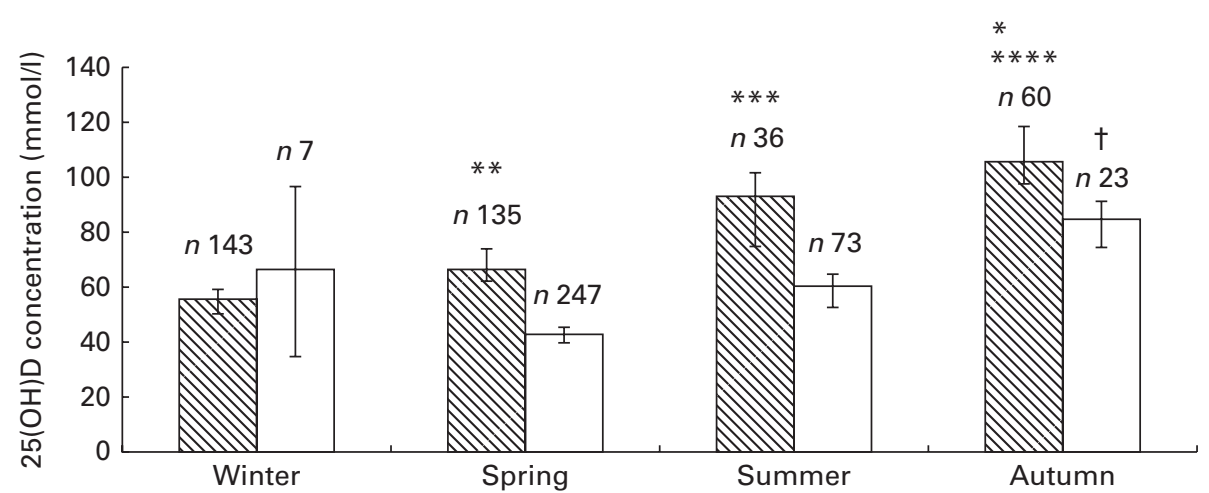

Fig. 1. 25-Hydroxyvitamin D (25(OH)D) concentration across four seasons in Africans $(\square)$ and Asian Indians $(\square)$. Values are means, with $95 \%$ confidence intervals represented by vertical bars. Results were adjusted for sex using ANCOVA. ${ }^{*}$ In Africans, mean value was significantly different from that for summer $(P<0.05)$. ${ }^{* *}$ In Africans, mean value was significantly different from that for winter $(P=0.005)$. ${ }^{* *}$ In Africans, mean value was significantly different from that for winter $(P=0.001){ }^{* \star \star \star}$ In Africans, mean value was significantly different from that for winter and spring $(P<0.001)$. $\dagger$ In Asian Indians, mean value was significantly different from that for spring and summer $(P<0.001)$.

\section{Supplementation and medication: Asian-Indian population}

In the Asian-Indian population, $22 \%$ of the subjects were on Ca supplementation and $15 \%$ were on vitamin D supplementation (Table 1). The median concentrations of $25(\mathrm{OH}) \mathrm{D}$ were higher in Asian-Indian subjects on vitamin D supplementation $(52 \cdot 2$ (IQR 32.7-73.2) v. $39 \cdot 2$ (IQR 26.9-55.1) nmol/1; $P<0 \cdot 001)$ or on Ca supplementation (54.2 (IQR 35.8-80.4) v. $37.5(\mathrm{IQR} 26.3-53.8) \mathrm{nmol} / \mathrm{l} ; \quad P<0.0001)$. The median concentrations of $25(\mathrm{OH}) \mathrm{D}$ in Asian-Indian males on statin therapy (49.3 (IQR 30.3-60.9) nmol/1) were not significantly different from those in males not on statin therapy $(45 \cdot 1$ (IQR 34.0-60.9) nmol/1; $P=0 \cdot 7$ ), but were higher that those in Asian-Indian females on statin therapy (52.2 (IQR $30 \cdot 1-80 \cdot 8) \mathrm{nmol} / \mathrm{l})$ compared with those in females not on statin therapy $(34 \cdot 4(\mathrm{IQR} 22 \cdot 4-52 \cdot 9) \mathrm{nmol} / \mathrm{l} ; P=0 \cdot 04)$.

\section{Supplementation and medication: African population}

In the African population, 3\% of the subjects were on $\mathrm{Ca}$ supplementation and $2 \%$ on vitamin D supplementation $(P<0.0001$ for both comparisons with the Asian-Indian population) (Table 1$)$.

\section{Dietary intake of calcium and vitamin D}

The median dietary $\mathrm{Ca}$ intake was significantly lower in the African subjects (223 (IQR 98.6-427) mg/d) than in the Asian-Indian subjects (336 (IQR 204-487) mg/d) $(P<0 \cdot 0001)$. The median dietary vitamin $\mathrm{D}$ intake was higher in the African subjects $(2.95$ (IQR $1.55-5.12) \mu \mathrm{g} / \mathrm{d})$ than in the Asian-Indian subjects $(1.17 \quad$ IQR $0.50-2 \cdot 11) \mu \mathrm{g} / \mathrm{d}) \quad(P<0.0001)$. Dietary vitamin D intake was $\geq 10 \mu \mathrm{g} / \mathrm{d}$ in $7.5 \%$ of the African subjects and $1.2 \%$ of the Asian-Indian subjects $(P=0 \cdot 008)$. Similarly, dietary Ca intake was $\geq 1000 \mathrm{mg} / \mathrm{d}$ in $4.5 \%$ of the African subjects and $\geq 1000 \mathrm{mg} / \mathrm{d}$ in $2.6 \%$ of the Asian-Indian subjects $(P=0 \cdot 002)$.

\section{Univariate analysis for associations with 25-hydroxyvitamin D concentrations}

The correlations of $25(\mathrm{OH}) \mathrm{D}$ concentrations with other variables are summarised in Table 2. Univariate analysis revealed that serum PTH concentrations were negatively correlated with $25(\mathrm{OH}) \mathrm{D}$ concentrations in both ethnic groups and weekly sun exposure score was significantly positively associated with $25(\mathrm{OH}) \mathrm{D}$ concentrations in the African subjects but not in the Asian-Indian subjects. In terms of body

Table 2. Spearman's correlations of 25 -hydroxyvitamin $\mathrm{D}(25(\mathrm{OH}) \mathrm{D})$ concentrations with other variables ( $\beta$ Coefficients)

\begin{tabular}{lcccc}
\hline & \multicolumn{2}{c}{$25(\mathrm{OH}) \mathrm{D}$ Africans $(n$ 371) } & \multicolumn{2}{c}{$\begin{array}{c}\text { 25(OH)D Asian-Indians } \\
(n \text { 343) }\end{array}$} \\
\cline { 2 - 5 } Variables & \multicolumn{1}{c}{$\beta$} & $P$ & & $P$ \\
\hline Age & 0.002 & 0.96 & 0.03 & 0.54 \\
PTH & -0.26 & $<0.0001$ & -0.23 & $<0.0001$ \\
Dietary Ca intake & 0.03 & 0.55 & 0.08 & 0.14 \\
Dietary vitamin D intake & -0.008 & 0.88 & 0.07 & 0.17 \\
BMl & -0.09 & 0.09 & -0.02 & 0.67 \\
eGFR & -0.07 & 0.20 & -0.16 & 0.002 \\
Visceral adipose tissue thickness & -0.18 & 0.0007 & 0.07 & 0.19 \\
Subcutaneous adipose tissue thickness & -0.12 & 0.02 & -0.07 & 0.17 \\
Whole-body fat & -0.11 & 0.04 & -0.07 & 0.20 \\
Weekly sun exposure score & 0.23 & $<0.0001$ & 0.02 & 0.67 \\
\hline
\end{tabular}

PTH, parathyroid hormone; eGFR, estimated glomerular filtration rate. 
Table 3. Multivariate regression models for 25-hydroxyvitamin D (25(OH)D)

(Standardised $\beta$-coefficients)

\begin{tabular}{|c|c|c|c|c|c|c|c|}
\hline $\begin{array}{l}\text { Regression } \\
\text { model no. }\end{array}$ & Ethnic group & $\begin{array}{l}\text { Dependent } \\
\text { variable }\end{array}$ & $\begin{array}{l}\text { Independent } \\
\text { variables* }\end{array}$ & $\beta$ & $P$ & $\begin{array}{l}R^{2} \dagger \text { for } \\
\text { full model }\end{array}$ & $P$ \\
\hline 1 & Africans ( $n$ 371) & $25(\mathrm{OH}) \mathrm{D}$ & $\begin{array}{l}\text { Season } \\
\text { PTH (pmol/l) } \\
\text { Weekly sun exposure }\end{array}$ & $\begin{array}{r}0.26 \\
-0.21 \\
0.10\end{array}$ & $\begin{array}{c}<0.0001 \\
<0.0001 \\
0.05\end{array}$ & $0 \cdot 16$ & $<0.0001$ \\
\hline 2 & Asian-Indians ( $n$ 343) & $25(\mathrm{OH}) \mathrm{D}$ & $\begin{array}{l}\text { Season } \\
\text { PTH (pmol/l) } \\
\text { Ca supplementation } \\
\text { Sex }\end{array}$ & $\begin{array}{r}0.12 \\
-0.17 \\
0.30 \\
0.21\end{array}$ & $\begin{aligned} & 0.02 \\
& 0.001 \\
< & 0.0001 \\
< & 0.0001\end{aligned}$ & 0.17 & $<0.0001$ \\
\hline
\end{tabular}

PTH, parathyroid hormone.

* Independent variables used are age, season of blood sample collection, smoking status, Ca and vitamin D supplementation, sex, estimated glomerular filtration rate, weekly sun exposure, PTH concentrations, and subcutaneous, visceral and whole-body fat. The following were log transformed: PTH and 25(OH)D. Season: winter was the reference season for the African subjects and spring was the reference season for the Asian-Indian subjects (see the statistical analysis section for a full description of the coding). Female sex was coded as 0 and male sex as 1 .

$\dagger R^{2}$ are unadjusted values.

composition, VAT and SCAT as well as total body fat were negatively associated with $25(\mathrm{OH}) \mathrm{D}$ concentrations in the African subjects. In the Asian-Indian subjects, none of the body composition variables was significantly associated with $25(\mathrm{OH}) \mathrm{D}$ concentrations. There was no significant association of $25(\mathrm{OH}) \mathrm{D}$ status with age and dietary Ca or vitamin D intake in either group.

\section{Predictors of 25-hydroxyvitamin D concentrations}

To assess the predictors of $25(\mathrm{OH}) \mathrm{D}$ concentrations in more detail, we carried out multivariate analyses (see Table 3). In the African subjects (see model 1), season of blood sample collection, PTH concentrations and weekly sun exposure score explained $16 \%$ of the variance in $25(\mathrm{OH}) \mathrm{D}$ concentrations. Season of blood sample collection and weekly sun exposure score were positive predictors of $25(\mathrm{OH}) \mathrm{D}$ concentrations, while PTH concentrations were negatively related to 25(OH)D concentrations.

Season of blood sample collection, PTH concentrations, sex and $\mathrm{Ca}$ supplement use explained $17 \%$ of the variance in $25(\mathrm{OH}) \mathrm{D}$ concentrations in the Asian-Indian subjects (see model 2, Table 3). Sex, season of blood sample collection and $\mathrm{Ca}$ supplement use were all positive predictors of 25(OH)D concentrations.

\section{Discussion}

To our knowledge, this is the first study to assess the determinants of $25(\mathrm{OH}) \mathrm{D}$ concentrations in African and Asian-Indian individuals living in Africa. As reported by Prentice et al. ${ }^{(31)}$, Africa is a heterogeneous continent with differences in latitude, climate, food availability, skin pigmentation and cultural practices. A systematic review of global vitamin D status by Wahl et al. ${ }^{(9)}$ has reported that there is a lack of data from many African countries. Mean concentrations ranging between 25 and $49 \mathrm{nmol} / 1$ have been reported by a single South African study $^{(32)}$, with higher concentrations being reported for West and Central Africa ${ }^{(9)}$. Hilger et al. ${ }^{(33)}$ reported similar findings in a more recent systematic review of vitamin D status in populations worldwide. We have shown that the prevalence of
$25(\mathrm{OH}) \mathrm{D}$ deficiency $(28.6 \%)$ is high in Asian-Indians living in Johannesburg and deficiency is rare in Africans (5\%) when using a cut-off value $<30 \mathrm{nmol} / 1$ to define deficiency.

Mithal et al. ${ }^{(10)}$ reported that $25(\mathrm{OH}) \mathrm{D}$ concentrations below $75 \mathrm{nmol} / \mathrm{l}$ are prevalent in every region of the world, while concentrations $<25 \mathrm{nmol} / 1$ are most common in South Asia and the Middle East. The definition of vitamin D deficiency and insufficiency and assay methodology vary across studies, which complicates comparisons. However, our findings of increased prevalence of vitamin D insufficiency in the AsianIndian population are in keeping with Mithal's findings.

Ethnicity has consistently been reported to be related to circulating $25(\mathrm{OH}) \mathrm{D}$ concentrations in $\operatorname{adults}^{(34,35)}$, and a high prevalence of hypovitaminosis $\mathrm{D}$ has been reported by several Indian studies ${ }^{(36-38)}$ as well as by studies carried out in Indian subjects in the $\mathrm{UK}^{(39)}$. The differences observed in $25(\mathrm{OH}) \mathrm{D}$ concentrations between the two ethnic groups in the present study probably reflect differences in diet, clothing and sun exposure.

Mean 25(OH)D concentrations in the African population were higher than those in the Cape Town population ${ }^{(32)}$ This may be because of differences in latitude and subject age as well as assays used to measure 25(OH)D concentrations. Concentrations were also higher than those observed in non-Hispanic Blacks and Mexican-Americans from the $\mathrm{USA}^{(40)}$, but much lower than those observed in the indigenous populations of East Africa ${ }^{(41)}$. It appears that urban Africans have lower $25(\mathrm{OH}) \mathrm{D}$ concentrations than rural individuals belonging to the older age groups (>50 years) ${ }^{(12)}$.

In spite of the fact that Johannesburg experiences between 8 and $9 \mathrm{~h}$ of sunshine throughout the year, we observed a clear seasonal variation in $25(\mathrm{OH}) \mathrm{D}$ concentrations in both ethnic groups, with autumn being a very significant positive predictor of $25(\mathrm{OH}) \mathrm{D}$ concentrations in both Asian-Indians and Africans. The concentrations of $25(\mathrm{OH}) \mathrm{D}$ were lowest in subjects from whom blood samples were collected in the months of JulySeptember (late winter and spring), indicating that sun exposure does influence $25(\mathrm{OH}) \mathrm{D}$ concentrations in both communities. Clear seasonal changes in $25(\mathrm{OH}) \mathrm{D}$ status, similar to our findings, have previously been reported in several different groups of individuals in South Africa such as the elderly with 
fractures ${ }^{(26)}$ and HIV-positive and -negative individuals from Cape Town ${ }^{(7)}$ as well as healthy African and Caucasian children living in Johannesburg ${ }^{(11)}$. In the present study, the sun exposure score was a predictor of $25(\mathrm{OH}) \mathrm{D}$ concentrations in the African population but not in the Asian-Indian population, in which females were mostly veiled. Using univariate regression analysis, weekly sun exposure score was found to be a significant predictor of $25(\mathrm{OH}) \mathrm{D}$ concentrations in the Asian-Indian population. However, after adjusting for age and sex, weekly sun exposure score was no longer a significant predictor of $25(\mathrm{OH}) \mathrm{D}$ concentrations in the Asian-Indian population. The sun exposure score comprises time spent outdoors as well as the extent of clothing coverage. It is possible that the time of day and the nature of time spent outdoors (e.g. physical activity) are also important for the determination of UV exposure, and these were not assessed in the present study. Together, these findings suggest that seasonal variation in $25(\mathrm{OH}) \mathrm{D}$ concentrations observed among the African and Asian-Indian subjects from Johannesburg is probably a result of both the time spent outdoors and the amount of clothing worn.

There was no significant association of $25(\mathrm{OH}) \mathrm{D}$ status with age in either group, while male sex was a predictor of higher $25(\mathrm{OH}) \mathrm{D}$ concentrations in the Asian-Indian population. We were unable to determine the reasons for this difference, but it is likely to be related to cultural practices such as wearing of the veil.

When total body fat and visceral and subcutaneous fat were included in the same regression model, neither total body fat nor body fat distribution was predictive of $25(\mathrm{OH}) \mathrm{D}$ concentrations in either group. We could find only one other study that has examined the relationship between body fat distribution and 25(OH)D concentrations in Asian-Indians ${ }^{(15)}$, and our findings are in contrast to the findings reported by Sulistyoningrum et $a l^{(15)}$. They demonstrated a negative association between visceral fat and $25(\mathrm{OH}) \mathrm{D}$ concentrations. The reasons for this difference are not known. However, there are major differences between the two studies: the AsianIndian population in Johannesburg is quite homogenous, having migrated from India, whereas the cohort described by Sulistyoningrum et $a l .^{(15)}$ originated in India, Pakistan, Bangladesh, Sri Lanka and Nepal. VAT and serum vitamin D concentrations were each measured in the two studies by different techniques; the sample size in the present study (343v. 192) was bigger. The mechanisms by which circulating concentrations of $25(\mathrm{OH}) \mathrm{D}$ are influenced by adipose tissue mass (or vice versa) are not fully understood. However, it is known that adipose tissue acts as a large depot for vitamin $\mathrm{D}^{(42)}$, which may in turn significantly affect $25(\mathrm{OH}) \mathrm{D}$ bioavailability $^{(43)}$. Furthermore, serum 25(OH)D concentrations of obese individuals exhibit a reduced response to UV-B radiation ${ }^{(43)}$ and oral vitamin D supplementation ${ }^{(44)}$ when compared with those of non-obese individuals. It is interesting to note that data from the National Health and Nutrition Examination Survey III suggest that the relationship between body fat and $25(\mathrm{OH}) \mathrm{D}$ concentrations is stronger in White people than in Black people ${ }^{(45)}$.
VAT is strongly associated with cardiometabolic diseases ${ }^{(46)}$. In South Africa, the mortality due to CVD and the prevalence of type 2 diabetes are higher in Asian-Indians than in Africans ${ }^{(47)}$. However, in the present study, the levels of VAT were found to be similar in these two population groups. This suggests that factors other than VAT are important contributors to cardiovascular risk in the Indian population.

Ca supplementation was positively predictive of $25(\mathrm{OH}) \mathrm{D}$ concentrations in the Asian-Indian subjects, while vitamin D supplementation was not. This discrepancy may be because of the presence of vitamin D in many Ca supplements, but the amount was not specifically quantified in the present study. Significantly more Asian-Indian participants than African participants were on Ca and vitamin D supplementation. We postulate that this may be due to differences in educational and socio-economic status. Dietary vitamin D intake was low because vitamin D content in most foods is naturally low and our estimates of vitamin D intake did not include the contribution from supplements. Consequently, the lack of a relationship between dietary vitamin $\mathrm{D}$ intake and serum $25(\mathrm{OH}) \mathrm{D}$ concentrations is not surprising and indicates sun exposure to be the major determinant of vitamin $\mathrm{D}$ status in these populations. In the present study, dietary $\mathrm{Ca}$ intake in both ethnic groups was found to be much lower than the $1000 \mathrm{mg} / \mathrm{d}$ intake level recommended by the National Osteoporosis Foundation of South Africa. Low Ca intake could result in poor vitamin D status because of increased $25(\mathrm{OH}) \mathrm{D}$ metabolism. Despite the low dietary Ca and vitamin D intake, the plasma concentrations of $25(\mathrm{OH}) \mathrm{D}$ were much higher in the African population than in the Asian-Indian population. This highlights the important contribution of sun exposure to $25(\mathrm{OH}) \mathrm{D}$ concentrations in this part of the world.

The concentrations of PTH were not significantly different between the ethnic groups, despite a high proportion of the Asian-Indian subjects having vitamin D deficiency. Attempts have been made to define optimal vitamin D status for bone health based on the relationship between PTH and 25(OH)D concentrations $^{(48)}$, and this relationship appears to vary by race $^{(49-51)}$. Thus, PTH concentrations in African-Americans are maximally suppressed at lower $25(\mathrm{OH}) \mathrm{D}$ concentrations compared with those in Whites ${ }^{(49)}$. The present study demonstrates that the significantly lower $25(\mathrm{OH}) \mathrm{D}$ concentrations in Asian-Indians compared with those in Africans occur in the presence of similar PTH concentrations. This finding further indicates that the relationship between 25(OH)D and PTH concentrations varies by race and that in terms of bone health optimal $25(\mathrm{OH}) \mathrm{D}$ concentrations may be different in each of these two population groups. However, further studies in which bone mineral density is measured in both ethnic groups and correlated with serum PTH and 25(OH)D concentrations are required to confirm this.

Our models explained between 16 and $17 \%$ of the variance in $25(\mathrm{OH}) \mathrm{D}$ concentrations, which is comparable to data obtained from previous studies ${ }^{(52-54)}$. Thus, McDonnell et $a{ }^{(53)}$ analysed data on non-food factors affecting vitamin D status and demonstrated that these explained only $13 \%$ of the variance in total $25(\mathrm{OH}) \mathrm{D}$ concentrations. Similarly, analysis of potential determinants of $25(\mathrm{OH}) \mathrm{D}$ in the US 
Radiologists Technologists Study has revealed that despite detailed data on UV radiation exposure being available, only $25 \%$ of the variance in $25(\mathrm{OH}) \mathrm{D}$ concentrations is explained ${ }^{(54)}$. Other factors that contribute to variance include skin colour ${ }^{(55)}$, physical activity ${ }^{(54)}$ and genetic factors ${ }^{(56)}$, none of which was assessed in the present study.

The strengths of the present study include the large sample size, the method used to measure plasma 25(OH)D concentrations, the multi-ethnic nature of the study participants, the determination of total body fat and body fat distribution, and the assessment of a large number of variables that are thought to influence vitamin D status. However, the present study has a number of limitations. First, due to the cross-sectional nature of the study, we could draw inferences as to the determinants, but could not definitively determine the causative nature of any associations. Second, we did not quantify vitamin D or Ca supplements and could therefore not accurately assess the contribution of these supplements to $25(\mathrm{OH}) \mathrm{D}$ concentrations. Furthermore, the dietary intake of Ca and vitamin D was limited to their quantification in fish, eggs and dairy products, but not in meat. We also did not assess physical activity that might influence the dermal synthesis of vitamin D and VAT and SCAT were determined by ultrasound and not by computed tomography scanning, which is the gold standard method. However, this method has been validated in this population ${ }^{(21)}$. The questionnaire used to assess sun exposure has been used in a number of studies ${ }^{(22,23)}$, but has not been validated against personal UV dosimetry or observed exposure. The limit of quantification for $25(\mathrm{OH}) \mathrm{D}_{2}$ was $11 \mathrm{nmol} / \mathrm{l}$, and because of this, $25(\mathrm{OH}) \mathrm{D}_{2}$ was not quantifiable in $9 \cdot 2 \%$ of the participants. In South African populations, $25(\mathrm{OH}) \mathrm{D}_{2}$ only constitutes a small proportion of total $25(\mathrm{OH}) \mathrm{D}$ and thus its lack of detectability in some subjects had little influence on the overall vitamin D status of the two ethnic groups. Finally, the number of subjects assessed in each season was not evenly distributed throughout the year.

The present study clearly demonstrates that any policy on vitamin D supplementation should be considered in a local context. Thus, season and, by implication, differences in weather conditions, dietary supplement use and ethnicity are all strong determinants of plasma $25(\mathrm{OH}) \mathrm{D}$ concentrations, and these factors, which vary widely across countries, must be considered before deciding on supplementation programmes. Adequate vitamin D concentrations in different population groups also require further study. In the present study, almost one-third of the Asian-Indians who participated were vitamin D deficient. It is possible that this group will benefit from routine supplementation. In view of the seasonal changes observed, further consideration should be given to whether year-long supplementation is required or whether supplementation can be restricted to winter and early spring. Studies are required to determine optimal dosages. The use of $\mathrm{Ca}$ was found to be associated with higher $25(\mathrm{OH}) \mathrm{D}$ concentrations in Asian-Indians, but the benefits and its impact on cardiovascular health have to be assessed $^{(27,57)}$. In conclusion, the present study demonstrates that there are major differences in $25(\mathrm{OH}) \mathrm{D}$ concentrations in apparently healthy adults living in Johannesburg, with the highest prevalence of $25(\mathrm{OH}) \mathrm{D}$ deficiency being observed in Asian-Indians. The important positive predictors of $25(\mathrm{OH}) \mathrm{D}$ concentrations in this population are supplementation and season.

\section{Acknowledgements}

The authors thank Dr C. Padoa for reading the manuscript as well as the staff of the Birth to Twenty Study for their assistance with data collection and the staff of the National Health Laboratory Services for helping with the analysis of all the samples.

The present study was supported by a self-initiated research grant from the Medical Research Council of South Africa and a large research grant from Carnegie Foundation. Siemens diagnostics supplied PTH kits. The funders played no role in study design, data collection and analysis, decision to publish the manuscript or preparation of the manuscript.

The authors' contributions are as follows: J. A. G. planned the study, analysed and interpreted the data, and wrote the manuscript; S. A. N. assisted with planning and study design; H. E. v. D. assisted with data analysis and interpretation and write-up; J. M. P. assisted with data interpretation and proofreading; N. J. C. analysed the data and assisted with proofreading and write-up.

None of the authors has any conflicts of interest to declare.

\section{References}

1. WHO (2010) WHO global tuberculosis control report 2010 Summary. Cent Eur J Public Health 18, 237.

2. Young F, Critchley JA, Johnstone LK, et al. (2009) A review of co-morbidity between infectious and chronic disease in Sub Saharan Africa: TB and diabetes mellitus, HIV and metabolic syndrome, and the impact of globalization. Global Health $\mathbf{5}, 9$.

3. Giovannucci E, Liu Y, Hollis BW, et al. (2008) 25-Hydroxyvitamin $\mathrm{D}$ and risk of myocardial infarction in men: a prospective study. Arch Intern Med 168, 1174-1180.

4. Pittas AG, Lau J, Hu FB, et al. (2007) The role of vitamin D and calcium in type 2 diabetes. A systematic review and meta-analysis. J Clin Endocrinol Metab 92, 2017-2029.

5. Lin J, Manson JE, Lee IM, et al. (2007) Intakes of calcium and vitamin D and breast cancer risk in women. Arch Intern Med 167, 1050-1059.

6. Schottker B, Haug U, Schomburg L, et al. (2013) Strong associations of 25-hydroxyvitamin D concentrations with all-cause, cardiovascular, cancer, and respiratory disease mortality in a large cohort study. Am J Clin Nutr 97, 782-793.

7. Martineau AR, Nhamoyebonde S, Oni T, et al. (2011) Reciprocal seasonal variation in vitamin D status and tuberculosis notifications in Cape Town, South Africa. Proc Natl Acad Sci U S A 108, 19013-19017.

8. Pludowski P, Holick MF, Pilz S, et al. (2013) Vitamin D effects on musculoskeletal health, immunity, autoimmunity, cardiovascular disease, cancer, fertility, pregnancy, dementia and mortality - a review of recent evidence. Autoimmun Rev 12, 976-989.

9. Wahl DA, Cooper C, Ebeling PR, et al. (2012) A global representation of vitamin D status in healthy populations. Arch Osteoporos 7, 155-172. 
10. Mithal A, Wahl DA, Bonjour JP, et al. (2009) Global vitamin D status and determinants of hypovitaminosis D. Osteoporos Int 20, 1807-1820.

11. Poopedi MA, Norris SA \& Pettifor JM (2011) Factors influencing the vitamin D status of 10-year-old urban South African children. Public Health Nutr 14, 334-339.

12. Kruger MC, Kruger IM, Wentzel-Viljoen E, et al. (2011) Urbanization of black South African women may increase risk of low bone mass due to low vitamin D status, low calcium intake, and high bone turnover. Nutr Res 31, 748-758.

13. McGill AT, Stewart JM, Lithander FE, et al. (2008) Relationships of low serum vitamin $\mathrm{D}_{3}$ with anthropometry and markers of the metabolic syndrome and diabetes in overweight and obesity. Nutr $J$ 7, 4 .

14. Liel Y, Ulmer E, Shary J, et al. (1988) Low circulating vitamin D in obesity. Calcif Tissue Int 43, 199-201.

15. Sulistyoningrum DC, Green TJ, Lear SA, et al. (2012) Ethnicspecific differences in vitamin D status is associated with adiposity. PLOS ONE 7, e43159.

16. Cheng S, Massaro JM, Fox CS, et al. (2010) Adiposity, cardiometabolic risk, and vitamin D status: the Framingham Heart Study. Diabetes 59, 242-248.

17. Ross AC, Manson JE, Abrams SA, et al. (2011) The 2011 dietary reference intakes for calcium and vitamin D: what dietetics practitioners need to know. J Am Diet Assoc 111, 524-527.

18. Hollis BW (2008) Measuring 25-hydroxyvitamin D in a clinical environment: challenges and needs. Am J Clin Nutr 88, 507S-510S

19. Richter LM, Norris SA \& De Wet T (2004) Transition from Birth to Ten to Birth to Twenty: the South African cohort reaches 13 years of age. Paediatr Perinat Epidemiol 18, 290-301.

20. Janssen MJ, Wielders JP, Bekker CC, et al. (2012) Multicenter comparison study of current methods to measure 25-hydroxyvitamin D in serum. Steroids 77, 1366-1372.

21. De Lucia Rolfe E, Norris SA, Sleigh A, et al. (2011) Validation of ultrasound estimates of visceral fat in black South African adolescents. Obesity (Silver Spring) 19, 1892-1897.

22. Hanwell HE, Vieth R, Cole DE, et al. (2010) Sun exposure questionnaire predicts circulating 25-hydroxyvitamin D concentrations in Caucasian hospital workers in southern Italy. J Steroid Biochem Mol Biol 121, 334-337.

23. Lee SH, Park SJ, Kim KM, et al. (2012) Effect of sunlight exposure on serum 25-hydroxyvitamin D concentration in women with vitamin D deficiency: using ambulatory lux meter and sunlight exposure questionnaire. Korean J Fam Med 33, 381-389.

24. Langehoven ML, Conradie PJ, Wolmarans P, et al. (1991) MRC Food Quantities Manual, 2nd ed., pp. 213. Parow: Medical Research Council.

25. MacLaughlin J \& Holick MF (1985) Aging decreases the capacity of human skin to produce vitamin $\mathrm{D}_{3}$. J Clin Invest 76, 1536-1538.

26. Pettifor JM, Ross FP \& Solomon L (1978) Seasonal variation in serum 25-hydroxycholecalciferol concentrations in elderly South African patients with fractures of femoral neck. $\mathrm{Br}$ Med J 1, 826-827.

27. Bostick RM, Kushi LH, Wu Y, et al. (1999) Relation of calcium, vitamin D, and dairy food intake to ischemic heart disease mortality among postmenopausal women. Am J Epidemiol 149, 151-161.

28. Millen AE, Wactawski-Wende J, Pettinger M, et al. (2010) Predictors of serum 25-hydroxyvitamin D concentrations among postmenopausal women: the Women's Health Initiative Calcium plus Vitamin D clinical trial. Am J Clin Nutr 91, $1324-1335$.
29. Cutillas-Marco E, Fuertes-Prosper A, Grant WB, et al. (2012) Vitamin D deficiency in South Europe: effect of smoking and aging. Photodermatol Photoimmunol Photomed 28, 159-161.

30. Zgaga L, Theodoratou E, Farrington SM, et al. (2011) Diet, environmental factors, and lifestyle underlie the high prevalence of vitamin D deficiency in healthy adults in Scotland, and supplementation reduces the proportion that are severely deficient. J Nutr 141, 1535-1542.

31. Prentice A, Schoenmakers I, Jones KS, et al. (2009) Vitamin D deficiency and its health consequences in Africa. Clin Rev Bone Miner Metab 7, 94-106.

32. Charlton KE, Labadarios D, Lombard CJ, et al. (1996) Vitamin D status of older South Africans. S Afr Med J 86, 1406-1410.

33. Hilger J, Friedel A, Herr R, et al. (2014) A systematic review of vitamin D status in populations worldwide. BrJ Nutr 111, $23-45$.

34. Shea MK, Houston DK, Tooze JA, et al. (2011) Correlates and prevalence of insufficient 25-hydroxyvitamin D status in black and white older adults: the health, aging and body composition study. J Am Geriatr Soc 59, 1165-1174

35. Forrest KY \& Stuhldreher WL (2011) Prevalence and correlates of vitamin D deficiency in US adults. Nutr Res 31, $48-54$.

36. Arya V, Bhambri R, Godbole MM, et al. (2004) Vitamin D status and its relationship with bone mineral density in healthy Asian Indians. Osteoporos Int 15, 56-61.

37. Harinarayan CV, Ramalakshmi T, Prasad UV, et al. (2007) High prevalence of low dietary calcium, high phytate consumption, and vitamin D deficiency in healthy south Indians. Am J Clin Nutr 85, 1062-1067.

38. Marwaha RK, Tandon N, Garg MK, et al. (2011) Vitamin D status in healthy Indians aged 50 years and above. $J$ Assoc Physicians India 59, 706-709.

39. Kift R, Berry JL, Vail A, et al. (2013) Lifestyle factors including less cutaneous sun exposure contribute to starkly lower vitamin D levels in U.K. South Asians compared with the white population. Br J Dermatol 169, 1272-1278.

40. Scragg R, Sowers M \& Bell C (2007) Serum 25-hydroxyvitamin D, ethnicity, and blood pressure in the Third National Health and Nutrition Examination Survey. Am J Hypertens 20, 713-719.

41. Luxwolda MF, Kuipers RS, Kema IP, et al. (2013) Vitamin D status indicators in indigenous populations in East Africa. Eur J Nutr 52, 1115-1125.

42. Rosenstreich SJ, Rich C \& Volwiler W (1971) Deposition in and release of vitamin $D_{3}$ from body fat: evidence for a storage site in the rat. J Clin Invest 50, 679-687.

43. Wortsman J, Matsuoka LY, Chen TC, et al. (2000) Decreased bioavailability of vitamin D in obesity. Am J Clin Nutr $\mathbf{7 2}$, 690-693.

44. Gallagher JC, Yalamanchili V \& Smith LM (2013) The effect of vitamin D supplementation on serum $25(\mathrm{OH}) \mathrm{D}$ in thin and obese women. I Steroid Biochem Mol Biol 136, 195-200.

45. Looker AC (2005) Body fat and vitamin D status in black versus white women. J Clin Endocrinol Metab 90, 635-640.

46. Britton KA, Massaro JM, Murabito JM, et al. (2013) Body fat distribution, incident cardiovascular disease, cancer, and all-cause mortality. J Am Coll Cardiol 62, 921-925.

47. Steinberg WJ, Balfe DL \& Kustner HG (1988) Decline in the ischaemic heart disease mortality rates of South Africans, 1968-1985. S Afr Med J 74, 547-550.

48. Dawson-Hughes B, Harris SS, Krall EA, et al. (1997) Effect of calcium and vitamin D supplementation on bone density in men and women 65 years of age or older. N Engl J Med 337 , $670-676$. 
49. Gutierrez OM, Farwell WR, Kermah D, et al. (2011) Racial differences in the relationship between vitamin $\mathrm{D}$, bone mineral density, and parathyroid hormone in the National Health and Nutrition Examination Survey. Osteoporos Int 22, $1745-1753$.

50. Aloia JF, Chen DG \& Chen H (2010) The 25(OH)D/PTH threshold in black women. J Clin Endocrinol Metab 95 , 5069-5073

51. Ginde AA, Liu MC, Camargo CA, et al. (2009) Demographic differences and trends of vitamin D insufficiency in the US population, 1988-2004. Arch Intern Med 169, 626-632.

52. Tran B, Armstrong BK, McGeechan K, et al. (2013) Predicting vitamin D deficiency in older Australian adults. Clin Endocrinol (Oxf) 79, 631-640.

53. McDonnell SL, French CB \& Heaney RP (2013) Quantifying the non-food sources of basal vitamin D input. J Steroid
Biochem Mol Biol (epublication ahead of print version 28 October 2013).

54. Freedman DM, Cahoon EK, Rajaraman P, et al. (2013) Sunlight and other determinants of circulating 25-hydroxyvitamin D levels in black and white participants in a nationwide U.S. study. Am J Epidemiol 177, 180-192.

55. Farrar MD, Kift R, Felton SJ, et al. (2011) Recommended summer sunlight exposure amounts fail to produce sufficient vitamin D status in UK adults of South Asian origin. $A m J$ Clin Nutr 94, 1219-1224.

56. Ahn J, Yu K, Stolzenberg-Solomon R, et al. (2010) Genomewide association study of circulating vitamin D levels. Hum Mol Genet 19, 2739-2745.

57. Bolland MJ, Barber PA, Doughty RN, et al. (2008) Vascular events in healthy older women receiving calcium supplementation: randomised controlled trial. BMJ 336, 262-266. 